\title{
Hume e a Experiência Singular
}

\author{
João Paulo Monteiro*
}

Resumo: Hume é conhecido por sua teoria da indução por repetição, mas em sua filosofia há lugar para inferências derivadas de experiências singulares. Parte do fundamento destas inferências depende de uma regra nentoniana, mas é preciso acrescentar a especificação do tipo de classe de objetos a que pertencem tanto a causa como o efeito - de um modo que pode esclarecer a exata natureza do "empirismo" humiano.

Palavras-chave: experiência - repetição - singular - inferência - indução

A experiência repetida tem na filosofia humiana do conhecimento um papel tão relevante e tão notório, que quase se arrisca a apagar o papel desempenhado nessa filosofia pela experiência singular. Os raciocínios causais, ou indutivos, não são apenas diretamente derivados de "conjunções constantes" ou "freqüientes", podem consistir também em inferências feitas a partir de um único exemplo do fenômeno examinado. Os textos falam por si.sós:

"Não apenas em filosofia, mas até na vida comum, podemos chegar ao conhecimento de uma determinada causa simplesmente a partir 
de um só experimento, desde que feito com critério, e após se descartarem cuidadosamente todas as circunstâncias estranhas e supérfluas" (Hume 6, p. 104; meu itálico).

É certo que estes raciocínios fundados em um só experimento parecem ter sua legitimidade, ou mesmo sua possibilidade, excluída por diversos outros textos do mesmo filósofo. Um exemplo:

"Quem tivesse visto apenas um corpo se mover sob o impulso de outro nunca poderia inferir que qualquer outro corpo seria movido por idêntico impulso" (ídem 5, p. 43; meu itálico) .

Os dois textos só aparentemente se contradizem. Ao contrário deste último, o primeiro é acompanhado pela referência a uma regra ou princípio antecedente, capaz de gerar a possibilidade de proceder a uma inferência a partir dessa experiência única:

"Embora aqui se suponha que temos apenas um experimento de um determinado efeito, temos contudo muitos milhões para nos convencer deste princípio, que objetos idênticos, colocados em circunstâncias idênticas, sempre proouzem efeitos idênticos" (idem 6, p. 105) .

Fica assim esclarecido que são possíveis as inferências incutivas a partir de experiências singulares, desde que se tenha o cuidado de considerar apenas o que é essencial nas circunstâncias do caso, afastando o que é estranho e supérfluo, e desde que se aplique ao caso um princípio geral herdado de um rico manancial de experiências repetidas anteriores. Tudo indica que, embora fique assegurado o primado da repetição, fica também estabelecido que a experiência repetida deve ser dispensada em todos os casos aos quais possa aplicar-se esse princípio geral.
O terreno que nos fazem pisar os comentadores da filosofia humiana que nesta se limitam a enfatizar o papel das conjuncões e experiências repetidas é, portanto, um terreno escorregadio. Um dos mais antigos desses comentadores parece mesmo ter-se enganado redondamente a esse respeito. Numa obra de 1805, Thomas Brown utiliza a questão da experiência singular como elemento de crítica à concepção humiana da indução. Partindo do estudo da Investigação (Enquiry), Brown censura Hume porque para este, conforme alega, a inferência causal "não surge na mente após um exemplo singular de sequiência, mas só depois de repetidos exemplos dessa mesma seqüência; pois não é numa observação única, nem num único resultado da experiência, que nos apoiamos para confiar plenamente que descobrimos uma causa" (Brown 1, p. 324 e segs.). Esta teoria atribuída a Hume por Thomas Brown é frontalmente desmentida pelo texto do Tratado aqui citado em primeiro lugar.

Este erro não costuma ser repetido pelos comentadores mais recentes, mas quando por exemplo Antony Flew se limita a dizer que para Hume os raciocínios indutivos são produtos de repetições (Flew 3, p. 94 e segs.), ou quando Deleuze afirma que para esse filósofo aqueles raciocínios vêm de uma experiência cuja "essência é a repetição de casos semelhantes" (Deleuze 2 , p. 64) ${ }^{(1)}$, ficam faltando esclarecimentos importantes. Tanto mais que 0 próprio Hume contribui pouco para esses esclarecimentos, e em sua formulação do problema usa uma linguagem onde se acentua apenas a importância da repetição, como no seguinte texto, que apresenta como a "conclusão de todo o assunto" da indução, e é o ponto de partida da equivocada análise de Brown:

"Toda crença em questões de fato e existência real deriva meramente de um objeto presente à memória ou aos sentidos e de uma conjunção costumeira entre ele e um outro objeto; ou por outras palavras, depois de constatar que, em muitos casos, quaisquer chas espécies de objetos, como a chama e o calor, ou a neve e o frio, sempre estiveram conjugadas, se a chama ou a neve se apresentarem nova- 
mente aos sentidos a mente é levada pelo costume a esperar o calor ou o frio, e a acreditar que essa qualidade existe e se manifestará se nos aproximarmos mais de perto" (Hume 5, p. 46) (2).

Seria ilusório supor que entre o Tratado de 1739 e esta Investigação de 1748 Hume tivesse modificado este aspecto da sua filosofia, passando na segunda dessas obras a concentrar-se exclusivamente no papel da experiência repetida, em detrimento do outro tipo de experiência. A tese acerca das inferências tiradas de experiências singulares é retomada quase nos mesmos termos na Investigação, embora esteja um pouco oculta numa nota da seção sobre a "Razão dos Animais", no quadro de uma comparação entre a cognição animal e a humana:

"Depois de vivermos algum tempo e nos acostumarmos à uniformidade da natureza, adquirimos um hábito geral pelo qual sempre transferimos o conhecido para o desconhecido, e concebemos este último como similar ao primeiro. Por meio desse princípio geral habitual, consideramos que mesmo um só experimento serve de fundamento para o raciocínio, e esperamos uma ocorrência similar com o mesmo grau de certeza, sempre que o experimento é feito com exatidão e livre de todas as circunstâncias estranhas" (id., ibidkm, p. 107; meu itálico) .

Creio ser este um texto suficientemente análogo ao do Tratado para não deixar qualquer dúvida quanto à identidade de conteúdo e significado existente entre ambos, para além de algumas diferenças de pormenor. Trata-se do mesmo tema da possibilidade de inferências tiradas de experiências singulares, com base num princípio mais geral que por sua vez depende de experiências repetidas - como é explicitado na referência ao hábito neste último texto ${ }^{(3)}$.
Mas qual é exatamente o caráter desse princípio geral, que sua primeira versão se traduzia na fómula "objetos idênticos produzem efeitos idênticos", e nesta outra dbra aparece como uma regra de "transferência do conhecido para o desconhecido"? É interessante notar que a fórmula do Tratado é equivalente à de uma outra "regra geral" apresentada mais adiante na mesma obra:

"A mesma causa produz sempre o mesmo efeito, e o mesmo efeito nunca surge a não ser da mesma causa" (Hume 6, p. 173) .

Esta é a quarta de uma série de oito regras destinadas a "julgar as causas e os efeitos", distinguindo entre os objetos que meramente surgem conjugados em nossa experiência e aqueles realmente ligados pela causalidade. Nem esta nem qualquer das outras sete se refere à possibilidade de inferências a partir do singular. Mas esta quarta regra e o princípio enunciado algumas dezenas de páginas antes deixam-se ambos resumir da mesma maneira: qualquer deles diz essencialmente que as mesmas causas produzem os mesmos efeitos. E na segunda está implícito o que vinha explicitado na primeira - que para tal é necessário as circunstâncias serem também as mesmas.

Trata-se portanto do mesmo princípio ou regra geral ("mesma causa, mesmo efeito"), mas o comentário da segunda formulação aponta para uma aplicação diferente:

"Quando por um claro experimento chegamos à descoberta das causas ou efeitos de qualquer fenômeno, imediatamente estendemos nossa observação a todos os fenômenos dessa mesma espécie, sem esperar por aquela repetição constante da qual deriva a primeira idéia dessa relação" (id., ibidem, pp. 173-174) . 
Ao dizer que é imediatamente que estendemos uma conclusão indutiva a outros fenômenos, este comentário não impõe a necessidade de qualquer nova experiência, repetida ou apenas singular, antes de tirar uma segunda conclusão, como aplicação da primeira. Só a repetição é aqui diretamente referida, mas não é apenas ela que se torna dispensável neste caso, é também a simples experiência singular. Esta regra não se destina a tornar esta última forma de experiência um fundamento suficiente para uma nova conclusão, dispensando a repetição; destina-se a possibilitar, dispensando qualquer forma de experiência, uma pronta e direta generalização.

Esta é uma questão que no Tratado é bastante obscura - o princípio ou regra (termos que no caso se equivalem) parece ser e ao mesmo tempo não ser o mesmo nos dois textos. Ou então, se em ambos seu significado é o mesmo, como é possível ter usos tão diferentes? É natural o engano de J.P. Wright, que cita todos estes textos humianos, e identifica a tal ponto as duas versões do princípio que supõe tratar-se também de "experimentos cruciais" no caso da "quarta regra" (Wright 14, p. 33) . Por outro lado, a Investigação não lança qualquer luz sobre o assunto, pois nela inexiste referência às oito regras metodológicas do Tratado. Ora só faz sentido falar de experimentos cruciais, ou algo equivalente, no caso da primeira versão da regra ou princípio, que tanto numa como noutra obra de Hume se destina a possibilitar experiências que, embora únicas, são decisivas, dando rápido acesso a novas conclusões. Mas não faz sentido falar de experimentos ou experiências de qualquer espécie no caso da mera generalização, feita imediatamente e sem derivar de qualquer nova experiência.

Quando uma relação de causalidade fica estabelecida a partir de uma experiência repetida, a operação indutiva realizada já inclui tacitamente aquela generalização, que é aplicada sempre que não há razões em contrário. No clássico exemplo humiano, a expectativa de que as bolas de bilhar continuem fazendo mover outras bolas de bilhar com as quais colidem, obviamente não se restringe aos movimentos futuros da bola ou bolas de que se teve experiência, mas abrange todos os movimentos atuais ou futuros de todos os objetos da mesma espécie (Hume 5, p. 33) . E a generalização é feita imediatamente, se logo se constata a inexistência de razões para dela nos abstermos. Faz parte das lições da experiência que depressa se aprenda a distinguir entre as classes de dojetos que permitem a generalização e aquelas em que é mais racional limitar nossas expectativas aos objetos já conhecidos.

O princípio ou regra de Hume, em qualquer de suas versões, evoca a célebre segunda regra de Newton: "Aos mesmos efeitos naturais devemos, tanto quanto possível, atribuir as mesmas causas" (Newton 11, p. 398) . Regra newtoniana que se reveste de um caráter metodológico, como princípio do raciocínio científico. Esta é a redação adotada pelo autor na segunda edição de seus Principia. Na primeira edição essa regra era apresentada em termos diferentes, além de ser chamada, juntamente com as outras três, "hipótese", e não "regra": "Os efeitos naturais da mesma espécie têm as mesmas causas" (idem 12, p. 166) . Compare-se também com outra versão de Hume, numa outra obra: "Efeitos idênticos derivam de causas idênticas" (Hume 4, p. 170) ${ }^{(4)}$.

Não nos podemos aqui deter nas diferenças entre o cunho mais ontológico da primeira versão da regra newtoniana, em 1687, e o caráter mais metodológico da versão de 1713, ou na maior proximidade das de Hume em relação à primeira. Também ficaria fora do âmbito deste estudo examinar as diferenças entre as regras ou princípios do Tratado, com seu foco principal na predição de efeitos a partir de causas, e, por outro lado, tanto as máximas newtonianas como as dos Diálogos, todas voltadas para a atribuição de causas a efeitos. Limitemo-nos a registrar que há um conceito central comum a todas as formulações dos dois autores: que as mesmas causas produzem os mesmos efeitos e os mesmos efeitos derivam das mesmas causas.

Ambas as versões da regra newtoniana, apesar das diferenças que há entre elas, são equivalentes no fato de terem o mesmo alcance da segunda das versões humianas: o da generalização imediata dos resultados das inferências, sem qualquer necessidade de um passo intermediário constituído 
por mais experiência, repetida ou singular. A regra newtoniana não se destina a possibilitar inferências do singular ou "experimentos cruciais", ao contrário do princípio humiano referido no Tratado em primeiro lugar.

Isso fica perfeitamente claro nos comentários tecidos por Newton a sua regra, dando exemplos de efeitos da mesma espécie que têm as mesmas causas: a respiração nos homens e nos animais, a queda dos corpos na Europa e na América, a reflexão da luz na Terra e nos outros planetas. Esses exemplos são os mesmos nas cuas ediçães e nas mesmas páginas citadas, e claramente nada têm a ver com inferências a partir de experiências singulares. Trata-se de classes de fenômenos cujas causas foram estabelecidas pela ciência - e a partir daí basta identificar cada fenômeno como pertencente a essa classe para logo sabermos qual é sua causa. Cada um deles, uma vez identificado como membro de uma determinada classe de fenômenos, é imediatamente - como vimos Hume afirmar - abrangido por uma generalização já tacitamente legitimada desde a descoberta da causa comm dessa classe de fenômenos. Identificado um fenômeno, ou efeito, como um caso de queda dos corpos ou de respiração, imediatamente podemos concluir que sua causa é a mesma que já conhecemos como causa de outros fenômenos análogos.

IV

O princípio geral citado primeiro no Tratado de Hume é realmente o mesmo que a quarta das oito regras gerais do capítulo posterior - a regra "newtoniana". O segundo caso é talvez o mais claro, quer por ser mais direto, quer por ser mais conhecido através de Newton, quer por ser o mais comum nas obras de Hume: "De um corpo com cor e consistência idênticas às do pão esperamos idêntica nutrição e sustento" (Hume 5, p. 37) ${ }^{(5)}$. Essas obras estão cheias de exemplos como este, onde os efeitos observados de um objeto são esperados no futuro, não só desse objeto, mas também de todos os similares. Mas não encontramos em Hume exemplos claros de indução a partir da experiência singular - embora a possibilidade desse tipo de incução seja, como vimos, explicitamente admitida. Além de estarem ausentes tais exemplos, também não há distinção nítida entre os casos em que o princípio "mesmas causas, mesmos efeitos" dá lugar a uma imediata generalização e aqueles em que serve de suporte a um raciocínio realizado a partir de uma experiência singular.

o problema da incução a partir de um único caso interessou também a Stuart Mill, um século depois de Hume: "Quando um químico anuncia a existência e as propriedades de uma substância recentemente descoberta, se confiarmos em sua exatidão sentimo-nos seguros de que as conclusões a que chegou serão mantidas universalmente, embora a indução esteja fundada em um único exemplo". Segundo Milll, só se recorre à repetição para garantir que esta experiência foi bem feita, e é assim que se torna possível inferir uma lei geral da natureza a partir de uma experiência singular. E Mill chega a mostrar um certo fascínio por esta questão, bem como pelo contraste entre a certeza de algumas inferências do singular e a relativa incerteza de algumas induções por repetição, ao concluir entusiasticamente: "Por que razão um único exemplo, em alguns casos, é suficiente para uma indução completa, enquanto, em outros casos, miríades de exemplos coincidentes, sem uma única exceção conhecida ou suposta, avançam tão pouco no sentido de chegar a uma proposição universal? Quem quer que possa responder a esta questão sabe mais de filosofia da lógica do que o mais sábio dos antigos, e terá resolvido o problema da indução" (Mill 10, pp. 205-206) .

Cabem aqui duas observações. A primeira é que Mill não parece ter consciência de que o problema da indução com um só exemplo já tinha sido formulado por Hume. A segunda é que a "solução" encaminhada pelo Sistema da Lógica passa pelo complexo aparelho da lógica indutiva, da indução eliminativa e dos métodos da investigação experimental. Mas o problema, na formulação humiana, também pode surgir no plano da vida comum, como se vê na passagem citada no início deste estudo. Questões como a da diferença entre os casos de generalização direta e os de indução com um só exemplo devem ser passíveis de soluções menos ambiciosas e mais simples.

Para tentar esclarecer essa distinção, podemos começar por perguntar como se caracteriza a classe de fenômenos a qual o princípio ou regra se pode aplicar. Partamos do exemplo humiano do pão e da nutrição. Por que 
podemos nós proceder imediatamente a uma generalização, esperando nutrição de todos os pães sem distinção, e não precisamos de qualquer nova experiência, repetida ou apenas singular? É porque essa classe de objetos se compõe exclusivamente de exemplos positivos, de objetos que sempre e sem exceção se mostraram nutritivos. Não se trata aqui apenas da diferença entre conjunção constante e conjunção freqüiente, diferença essa que em outros contextos tem a maior relevância para Hume (Hume 5, p. 57 e segs.) . Em termos humianos, não há dúvida de que a conjunção, no caso em pauta, precisa de ser constante para que possamos ter uma expectativa que não seja o que hoje chamaríamos uma expectativa "probabilística" ou "estatística". Mas pode ocorrer que essa conjunção constante - e este é o ponto fundamental - se verifique apenas em um dos tipos de objeto de uma determinada classe. Por exemplo, se a classe constituída pelos pães se dividisse em dois tipos, sendo os membros de um desses tipos sempre nutritivos e o outro não tendo nunca esse efeito, não mais bastaria constatarmos que um objeto é membro dessa classe de objetos para imediatamente lhe atribuirmos um poder nutritivo.

Claro que na classe dos pães não há realmente essa divisão em dois tipos, um positivo e outro negativo - ou, e é o que importa, é isso que Hume supõe. Mas há outras classes de objetos que apresentam essa divisão, entre um tipo de subclasse apresentando essa característica positiva e outro tipo não a apresentando, ou seja, sendo "negativo" quanto ao efeito em questão. Tomemos por exemplo a classe dos metais, que se divide em diversas subclasses - ouro, ferro, alumínio, etc. -, e experimentemos riscar vários fragmentos de algumas dezenas de metais com um outro mineral ainda desconhecido, que por hipótese não sabemos se será ou não capaz de riscar algum desses fragmentos de metal. Se ao final de uma série de experiências suficientemente longa, repetida e variada, tivermos constatado que esse mineral risca uma dezena de metais, sempre, enquanto a outra dezena não risca nunca, teremos reunido, para qualquer experiência futura no mesmo campo, as condições suficientes para que um experimento singular, sem necessidade de repetição, conduza a uma nova descoberta e permita uma conclusão indutiva - ao mesmo tempo em que estaremos numa situação em que essa experiência se torna necessária.
Necessária, porque se acharmos alguns exemplares de uma nova subclasse ou espécie de metal, e quisemos saber se os membros dessa nova subclasse vão ser riscados pelo nosso mineral, estaremos numa situação cognitiva muito diferente de se acharmos alguns exemplares de uma nova espécie de pão. Neste último caso não temos qualquer razão para hesitar em aplicar a regra newtoniana, generalizando imediatamente os conhecimentos que temos acerca dessa classe de objetos de maneira a abranger o novo achado, juntamente com todos os outros membros dessa mesma subclasse que venhamos a achar no futuro. Para nós a classe dos pães compõe-se de subclasses que podem ter muitos aspectos diferentes entre si, sendo inclusive uns mais nutritivos do que outros, mas, acertadamente ou não, acreditamos que todas essas subclasses são de fato alimentícias - ou seja, pertencem todas ao mesmo tipo positivo. Não havendo razão para admitir a hipótese negativa, isto é, para supor que existem pães não nutritivos, nossa generalização é feita prontamente. Mas, quanto à nova espécie de metal, não sabemos se pertence ao tipo positivo ou ao tipo negativo - e precisamos da experiência para decidir.

A experiência torna-se aqui necessária - mas é suficiente realizá-la uma só vez. Porque nossa decisão, antes disso, já se encontra circunscrita a apenas cluas hipóteses, duas possibilidades, se tivermos aprendido a lição indutiva das experiências (essas, repetidas) que fizemos com exemplares das diversas subclasses ou espécies conhecidas da classe dos metais. Uma das coisas que teremos aprendido é que nessa classe todos os objetos, de qualquer subclasse, pertencem a um de dois tipos: o positivo ou o negativo. ou seja, que não existe - é o que supomos - qualquer metal que se comporte irregularmente perante nossas tentativas de riscá-lo, ou seja, não há subclasse cujos membros umas vezes se deixem riscar e outras não. Ora, para escolher apenas entre a hipótese negativa e a positiva, excluída que ficou a hipótese da irregularidade, não há qualquer razão para proceder ainda a experiências repetidas. Basta uma só vez, porque se esse fragmento de um novo metal puder ser riscado é porque pertence ao tipo positivo, pois obviamente ficou excluída a possibilidade de ele pertencer ao tipo negativo. Ou seja, de algum modo foram postas de lado as "circunstâncias estranhas e supérfluas". A primeira hipótese foi a única que restou, por exclusão de partes, e por uma 
espécie de experimento crucial, e por isso seria destituído de sentido exigir ainda que ela fosse confirmada por repetidas experiências.

Hume tinha razão ao afimar que a inferência feita a partir de um caso único se opera pela aplicação do princípio "mesma causa, mesmo efeito". Mas não estabeleceu distinção entre este caso e o da simples e imediata generalização a partir do mesmo princípio. Nem acrescentou, como agora podemos fazer, que um experimento fica "livre de circunstâncias estranhas", de modo que conduza isoladamente a uma conclusão indutiva, sem necessitar da repetição, quando a classe sob investigação se divide da maneira agora indicada, tomando possível a decisão crucial entre apenas duas possibilidades. Uma decisão que sem dúvida é obtida por dedução a partir de algumas premissas - mas é igualmente claro que estas últimas só poderiam ser obtidas a partir da experiência repetida, por indução enumerativa. E é aqui indiferente que se tenha chegado a essa situação através de um criterioso trabalho de investigação experimental, ou que a natureza já assim espontaneamente se nos apresente.

Mas em que casos a experiência singular deixa de ser suficiente para uma conclusão indutiva? Se supusermos agora que o dbjeto de nossa interrogação é por exemplo um certo animal, ou uma certa espécie animal, e que o fenômeno a investigar é a reação desse animal ou espécie a um determinado ruído, é evidente que se nos limitarmos a examinar o animal nada poderemos concluir. Mas também não será suficiente proceder a uma experiência singular, produzindo uma só vez esse ruído e observando o comportamento daí resultante. Porque a classe "reações de animais a ruídos" nem é uniforme nem se divide apenas em dois tipos de subclasses: divide-se em três. Além dos casos negativos (os que nunca fogem ao ouvir esse ruído), há pelo menos um terceiro tipo: o dos que umas vezes fogem desse ruído e outras não, ou seja, "fenômenos irregulares", ou regulares mas apenas "estatísticos", "freqüenciais" ou "probabilísticos" - no máximo. Portanto essa classe de fenômenos não permite que uma experiência singular decida o problema, levando a uma conclusão indutiva. Mas se pudermos submeter o animal a uma experiência que, além de controlada e cuidadosa, seja repetida um número suficiente de vezes, haverá um momento a partir do qual poderemos considerar irracional continuar hesitando, se o comportamento dele for, sempre e em todos os casos, de fuga ao ouvir o ruído, e a partir do qual decidiremos reconhecer a conclusão indutiva que se impõe: que no futuro esse animal, ou essa espécie de animal, fugirá sempre ao receber esse estímulo. Da mesma causa esperaremos o mesmo efeito.

Esta análise de modo algum se pretende exaustiva do problema. Certamente que para a solução deste ponto de interpretação de Hume poderão ser construídos modelos diferentes do "modelo tripartido" aqui proposto com um tipo "positivo", um tipo "negativo" e um tipo "irregular", como únicos tipos constitutivos de uma classe sob exame, quanto aos problemas do recurso à experiência repetida ou singular para chegar a conclusões indutivas. O objetivo da presente análise consiste apenas em contrastar o caso em que é possível e legítima a inferência tirada da experiência singular com outros dois casos nítidos: aquele em que ela ainda não é necessária, que é a classe uniforme de fenômenos, e aquele em que ela já não é suficiente, que é a classe tripartida. O primeiro caso pareceu-nos particularmente interessante, por ser aquele a que realmente pode ser referida a segunda formulação da regra newtoniana no Tratado humiano, em contraste com uma primeira formulação aplicada pelo filósofo ao problema da experiência singular.

Não há qualquer ambigüidade no Tratado quanto à necessidade dessa regra, como uma das condições de possibilidade das inferências a partir de experiências singulares. Onde a ambigüidade se instala é no fato de a mesma regra ser também aquela que preside à simples aplicação de generalizações, sem qualquer nova experiência. Podemos agora admitir que essa regra efetivamente preside aos dois tipos de operação, o primeiro nos casos em que a classe de fenômenos é uniforme e o segundo nos casos em que essa classe é "bipartida", contendo apenas um tipo positivo e um tipo negativo de subclasse. 
Esse argumento pode ser usado para esclarecer uma outra passagem de Hume. Na Investigação aparece o seguinte exemplo, imediatamente antes da conclusão quanto ao problema da incução:

"Depois de uma criança experimentar uma sensação de dor ao tocar na chama de uma vela, passará a ter o cuidado de nunca mais pôr a mão perto de qualquer vela; pois esperará um efeito similar de uma causa que é similar em sua aparência e qualidades sensíveis" (Hume 5, p. 39) .

Este é um texto que pode ser analisado sob vários aspectos, mas a interpretação que parece se impor é aquela que vê aqui um exemplo de inferência a partir de uma experiência singular. Está implícito que se trata da primeira vez que essa criança põe a mão na chama de uma vela - e a conclusão é tirada a partir de uma só experiência. Num caso como este, supor a necessidade de repetir a experiência ficaria até tingido de ridículo... Mas nada permite concluir que é o caráter traumático dessa experiência que leva à conclusão inoutiva. Não se trata de evitar um perigo, trata-se de uma expectativa gerada por inferência indutiva, como se vê na segunda parte do texto ${ }^{(6)}$. Mas Hume não esclarece como neste caso se prescinde daquela experiência repetida que nessa mesma obra, e nas páginas seguintes, nos vai apresentar como fundamental para o raciocínio indutivo.

Se aplicarmos a este caso o nosso modelo, poderemos concluir que o que torna possível a inferência acerca da vela é a aplicação da regra newtoniana a um caso em que a simples observação não podia revelar a uma criança, ainda sem qualquer experiência dos perigos das chamas, que aquele objeto colorido e brilhante lhe iria causar dor, e que ao mesmo tempo a classe de fenômenos relevante se prestava à aplicação dessa regra, só com a ajuda de uma experiência singular, sem necessidade de repetição. Que classe de fenômenos? Só pode ser um conjunto mais amplo do que o das velas e das chamas - uma classe da qual estas possam ser, face à experiência passada dessa criança, encaradas como casos particulares.
Essa classe pode ser algo como os "objetos tocados" que povoaram essa experiência. É de supor que a criança tenha tocado vários objetos, e que a classe constituída por estes inclua um tipo formado por aqueles que não procuziram qualquer dor (o tipo negativo) e um tipo fomado por aqueles que produziram alguma espécie de dor. Se supusermos também que não existe nesse caso, ou que não foi considerado, qualquer outro tipo de fenômeno do gênero "objeto tocado", podemos considerar o exemplo humiano como um caso de inferência do singular, tornado possível pelo fato de a classe relevante de fenômenos se dividir em apenas dois tipos, conforme o modelo aqui analisado.

A partir dessa "base empírica", constituída, sem dúvida, por experiências repetidas, basta uma operação elementar e quase automática para chegar a uma conclusão indutiva baseada nessa única e singular experiência. Se a chama causa dor é porque obviamente não pertence ao tipo negativo. Logo, pertence ao tipo positivo, cujos membros causam sempre dor. De onde se segue, agora dedutivamente, que a chama que uma vez causou dor vai sempre continuar fazendo isso a quem a tocar. Esta chama e, por generalização, todos os objetos da mesma espécie, todas as chamas nunca mais essa criança se chegará a uma vela acesa. Assim, não é indispensável que uma expectativa como essa, mesmo sob a forma extremamente geral expressa na proposição "todo fogo causa dor", se constitua a partir da experiência repetida.

VI

O problema da inchucão com um só exemplo e do papel da experiência singular no conhecimento foi objeto de variadas interpretações curante os séculos XVIII e XIX. Em nosso século, Nicod e Lalande (Nicod 13; Lalande 8) deram-lhe soluções que possivelmente deveriam ser diretamente referidas à filosofia de David Hume - mas não é aqui o lugar para desenvolver 
esse tema, pois para tal seria necessário todo um outro estudo. Os nossos limites terão que ser aqui os da análise interna dessa filosofia e da discussão do alcance que lhe pode ser atribuído.

Uma consequiência deste aspecto da filosofia humiana da indução é que o papel da repetição em cada sujeito, em cada história individual de aquisição de conhecimentos acerca do mundo real, aparece como inteiramente contingente. Ou seja, não é necessário que as inferências indutivas concretas, feitas por cada indivíduo concreto, derivem de experiências repetidas de modo predominante, e muito menos exclusivo, no decurso de sua existência como sujeito cognoscente. Em princípio, bastariam algumas inchções enumerativas de caráter muito geral para constituir uma estrutura fundamental, um "esquema do mundo" formado por proposições acerca de grandes classes de fenômenos, estrutura que iria sendo completada com o recurso a experiências singulares, apenas com ocasional e escasso recurso a experiências repetidas. Esta foi uma consequiência que Hume não tirou das premissas contidas em sua filosofia. Mas julgo estar claro agora que ela poderia ser tirada - e, não sem ironia, dedutivamente.

Abstract: Hume's theory of induction by repetition is well known, but there is room in his philosophy for inductions from single experiments. Part of the foundation of such inferences depends on a Newtonian rule, but we must specify the type of class of objects to which both the cause and the effect belong - so that the precise nature of Humean "empiricism" may be clarified.

Key-words: experience - repetition - singular - inference - induction

\section{Notas}

(1) Outra expressão que se presta a equívocos: "Sem conjunção constante, sem experiência passada formando hábito, não há inferência causal" (Malherbe 9, p. 125) .

(2) Cf. Flew 3, p. 93.

(3) Como escreveu em 1879 um outro antigo comentador: "O que Hume quer dizer com 'costume' ou "hábito' é apenas a repetição das experiências" (Huxley 7, p. 116) .

(4) Ou ainda: "Efeitos idênticos provam causas idênticas" (Hume 4, p. 165).

(5) Este exemplo é apresentado como uma aplicação de uma outra versão da regra newtoniana: "De causas que parecem similares esperamos efeitos similares" (Hume 5, p. 36).

(6) Não se Ihe aplicariam, por exemplo, comentários como este feito por Flew em outro contexto: "Gato escaldado de água fria tem medo ('Once bitten, twice shy') . Una só experiência realmente traumática é aparentemente suficiente para formar um ansioso hábito de expectativa" (Flew 3, p. 95).

\section{Bibliografia}

1. Brown, T. Observations on the Nature and Tendency of the Doctrine of Mr. Hume Concerning the Relation of Cause and Effect. In: Brown, R. Between Hume and Mill. N. York, ed. The Modern Library, 1970.

2. Deleuze, G. Empirisme et Subjectivité: Essai sur la Nature Humaine selon Hume. Paris, Presse Universitaire de France, 1953. 
3. Flew, A. Hume's Philosophy of Belief. Londres, Routledge \& Kegan Paul, 1961.

4. Hume, D. Dialogues Concerning Natural Religion. N. York, Bobbs-Merrill, 1947.

5. _. An Enquiry Concerning Human Understanding (Enquiry). Oxford, Clarendon Press, 1975.

6. . A Treatise of Hrman Nature (Treatise) . Oxford, Clarendon Press, 1958.

7. Huxley, T. Hume. Londres, Macmillan and Co., $2^{\mathrm{a}}$ ed., 1984.

8. Lalande, A. Les Théories de l'Induction et de l'Expérimentation. Paris, Boivin, 1929.

9. Malherbe, M. La Philosophie Empiriste de David Hume. Paris, Vrin, 1976.

10. Mill, J.S. A System of Logic, Ratiocinative and Inductive, III. Londres, Longmans, 1959.

11. Newton, I. Mathematical Principles of Natural Philosophy. Trad. A. Mbtte, Berkeley, University of California Press, 1946.

12. . Princípios Matemáticos da Filosofia Natural. Trad. P.R. Mariconda, São Paulo, col. Os Pensadores, Nova Cultural, 1987.

13. Nicod, J. Le Problème Logique de I'Induction. Paris, Alcan, 1924.

14. Wright, J.P. The Sceptical Realism of David Hume. Minneapolis, University of Minnesota Press, 1983. 